\title{
Reflexões sobre Formação de Trabalhadores por meio da UAB no Pará
} Reflections on Training of Workers through UAB in Pará

\section{João Batista do Carmo Silva*1 \\ Marlanje Solene Ferreira ${ }^{1}$ \\ Benilda Miranda Veloso Silva²}

${ }^{1}$ Faculdade de Educação/CUNTINS/UFPA. Endereço: Tv. Padre Antônio Franco 2617 - Bairro da Matinha. Cametá - PA - Brasil. *jbatista@ufpa.br

${ }^{2}$ SEDUC / Pará.

Endereço: Av. Augusto Montenegro, s/n- Km 10 - Icoaraci - Belém - PA - Brasil.

\section{Resumo}

Este artigo analisa a relação entre a formação dos trabalhadores egressos do Polo Cametá da Universidade Aberta do Brasil (UAB) e o seu perfil socioeconômico, a sua inserção/manutenção no mercado de trabalho, a sua situação laboral e o seu grau de satisfação com a área de formação. O referencial teórico está fundamentado em autores de concepção crítica. A metodologia desta pesquisa foi orientada pelo Materialismo HistóricoDialético com Abordagem Qualitativa, tendo como procedimento técnico o Estudo de Caso. Os resultados da pesquisa explicitam que o Polo da UAB tem uma importante função social na formação do trabalhador da microrregião de Cametá e que a maioria dos trabalhadores egressos não atua em sua área de formação, mas, contraditoriamente, sentem-se satisfeitos com a formação recebida. Conclui-se que a UAB/Polo Cametá, por meio da EaD, contribuiu positivamente no processo formativo dos trabalhadores egressos, proporcionando uma formação profissional e humana.

Palavras-chave: Trabalho. Universidade. Formação. Educação a distância. Egressos.

\section{(c) (i)}

Recebido 12/08/2020 Aceito 24/02/2021

Publicado 26/02/2021

\section{COMO CITAR ESTE ARTIGO}

ABNT: SILVA, J. B. DO C.; FERREIRA, M. S.; SILVA, B. M. V. Reflexões sobre Formação de Trabalhadores por meio da UAB no Pará. EaD em Foco, v. 11, n. 1, e1162, 2021. DOI : https://doi.org/10.18264/eadf.v11i1.1162 


\section{Reflections on Training of Workers through UAB in Pará}

\section{Abstract}

This article analyzes the relationship between the training of workers graduating from Polo Cametá of the Universidade Aberta do Brasil (UAB) and their socioeconomic profile, their insertion and maintenance in the labor market, their employment situation and their degree of satisfaction with the training area. The theoretical framework is based on authors of critical conception. The methodology of this research follows the Historical-Dialectical Materialism with Qualitative Approach, and has as a technical procedure the Case Study. The results of the research demonstrate that the UAB Pole has an important social function in the training of workers in the microregion of Cametá (Pará, Brazil) and that most of the former workers do not work in their training area, but, contradictorily, they feel satisfied with the training received. It is concluded that the UAB / Polo Cametá, through distance education, contributed positively in the training process of graduates, providing professional and human training.

Keywords: Work. University. Formation. Distance education. Graduates

\section{Introdução}

Neste artigo, discutimos as contribuições da Universidade Aberta do Brasil (UAB/Polo Cametá) - instituição pública de Ensino Superior, instalada no município de Cametá (PA), que desenvolve a formação acadêmica por meio da modalidade de Educação a Distância (EaD) - para os seus egressos que se tornaram trabalhadores. Para isso, identificamos o número de alunos formados no período de 2014 a 2018, realizamos um levantamento do perfil socioeconômico dos trabalhadores egressos e investigamos se o processo formativo contribuiu para a inserção/manutenção desses sujeitos no mercado de trabalho, assim como investigamos a situação laboral dos egressos e o seu grau de satisfação com a área de formação.

A indagação científica da pesquisa é relevante, tendo em vista que "raros são os estudos visando ao acompanhamento de egressos de cursos de graduação" (ANDRIOLA, 2014, p. 207). Por isso, é necessário discutir o processo formativo dos egressos para averiguar a qualidade da formação recebida, principalmente por se tratar da EaD, que, apesar de ser uma modalidade que vem se expandindo muito nos últimos anos no Brasil (ARRUDA; ARRUDA, 2015), ainda é alvo de críticas.

Logo, é necessário discutir a respeito da inserção e manutenção desses sujeitos no mercado de trabaIho no contexto das políticas neoliberais e da globalização do capital, onde o trabalho está submetido aos interesses deste, conforme mostra Antunes (2009). Por isso, considerando as mudanças associadas ao trabalho ao longo da história e sua importância na formação da identidade dos trabalhadores, este artigo se propõe a responder à seguinte questão: a formação ofertada pela UAB/Polo Cametá, por meio da EaD, contribuiu para uma atuação profissional e humana dos trabalhadores egressos?

Com base no exposto, este artigo organiza-se nas seguintes seções: introdução; procedimentos metodológicos; trabalho, universidade e educação a distância; a UAB e a formação do trabalhador; perfil e inserção/manutenção no mercado de trabalho; conclusão e, por fim, referências, nas quais são informadas as fontes de consulta utilizadas para o aporte teórico desta pesquisa. 


\section{Procedimentos Metodológicos}

Quanto ao aspecto metodológico, a pesquisa foi realizada no Município de Cametá - pertencente à mesorregião do nordeste paraense e a microrregião de Cametá; apresenta uma área territorial correspondente a 3.081,367 km2, com uma população estimada em 2020 de 139.364 habitantes (IBGE, 2020) - tendo como lócus de investigação a UAB/Polo Cametá, uma instituição pública de Ensino Superior que oferta cursos de formação na modalidade EaD, cuja singularidade reside no fato de ser o único Polo Público e Gratuito em EaD nesse município.

Para o acesso às informações sobre o objeto de estudo, que é o processo formativo do trabalhador por meio da EaD, selecionamos os sujeitos da pesquisa: trabalhadores egressos de dois cursos da UAB/Polo Cametá: Licenciatura em Matemática e Bacharelado em Administração Pública, com um recorte histórico de 2009, ano de implantação do Polo, até o ano de 2018.

Quanto à fundamentação epistemológica, adotamos, nesta pesquisa, um posicionamento teórico embasado no Materialismo Histórico-Dialético, uma vez que esse método permite analisar as relações dialéticas entre o sujeito, o objeto e o lócus da pesquisa, buscando a essência do fenômeno, aquilo que está subjacente às aparências, ou seja, o caráter conflitivo, dinâmico e histórico da realidade (FRIGOTTO, 1991).

Esta pesquisa, segundo a abordagem do problema, é qualitativa e seu procedimento técnico é o Estudo de Caso, por ter características específicas como a hierarquização das ações de descrever, compreender e explicar a precisão das relações entre o global e o local, a aproximação do objeto de estudo e, principalmente, a busca de resultados que são os mais fidedignos possíveis.

Realizamos três etapas de procedimentos para a coleta de dados: a pesquisa bibliográfica, a pesquisa documental e a pesquisa de campo, sendo que uma articula-se à outra. Segundo Gerhardt e Silveira (2009), a pesquisa bibliográfica é feita a partir do levantamento de referências teóricas já analisadas e publicadas, como livros, artigos, dissertações, entre outros. É preciso ressaltar que o levantamento bibliográfico realizado teve como finalidade a formação da base teórico-conceitual, para a qual selecionamos autores como Saviani (2007), Antunes (2009), Severino (2008), Andriola (2014), Arruda e Arruda (2015), Custódio et al. (2019), Oliveira e Santos (2020), Mendonça et al. (2020), entre outros.

A pesquisa documental, etapa muito significativa desta pesquisa, recorreu a fontes como tabelas estatísticas, legislações, documentos oficiais, relatórios. Segundo Ludke e André (1986, p. 39), “(...) os documentos constituem também uma fonte poderosa de onde podem ser retiradas evidências que fundamentem afirmações e declarações do pesquisador". Diante disso, afirmamos que a análise documental realizada complementou as informações obtidas por outras técnicas e deu estabilidade aos resultados.

Quanto à pesquisa de campo, de acordo com Marconi e Lakatos (2003), esta é utilizada com o objetivo de conseguir conhecimentos acerca de um problema, para o qual se procura uma resposta. Dessa maneira, adotamos como instrumento de coleta de dados a aplicação das seguintes técnicas: questionário fechado e entrevista semiestruturada. Esses dois instrumentos têm em comum, segundo Rudio (2007), o fato de serem constituídos por uma lista de indagações que, ao serem respondidas, dão ao pesquisador as informações necessárias que ele pretende atingir.

Optamos pela aplicação do questionário via internet com a população de trabalhadores egressos das quatro turmas analisadas, e tivermos um retorno de 35\%. Já o questionário buscou averiguar, no primeiro momento, o perfil dos trabalhadores egressos (sexo, faixa etária, estado civil, moradia, escolaridade, renda, etc.), depois investigar a situação laboral destes e o seu grau de satisfação com a área de formação.

A entrevista semiestruturada foi realizada com uma amostragem dos trabalhadores egressos, sendo selecionados, inicialmente, oito sujeitos com base nos seguintes critérios: idade (sujeitos com maior e 
com menor idade); tempo de serviço (sujeitos com maior e com menor tempo de serviço); e escolaridade (sujeitos com maior e com menor nível de escolaridade).

Devido à dificuldade de acesso aos egressos que tivemos, foram contatados apenas cinco sujeitos, que foram os seguintes: Egresso A, sujeito com maior idade; Egresso B, sujeito com maior tempo de serviço; Egresso C, sujeito com menor tempo de serviço; Egresso D, sujeito com maior nível de escolaridade; e Egresso E, sujeito com menor nível de escolaridade.

Com os dados coletados, foi realizada a sistematização e análise destes, com base na Análise de Conteúdo (AC), que é um procedimento de pesquisa situado em um delineamento amplo da teoria da comunicação. Além disso, a AC requer que as descobertas tenham relevância teórica, implicando comparações contextuais que devem obrigatoriamente ser direcionadas a partir da sensibilidade, da intencionalidade e da competência teórica do pesquisador (FRANCO, 2008). Inferimos, portanto, que a técnica da análise de conteúdo auxiliou no aprofundamento e na melhora da qualidade da interpretação, assim como na ampliação do entendimento sobre o objeto de estudo da pesquisa.

\section{Trabalho, Universidade e Educação a Distância}

Trabalho e educação, segundo Saviani (2007), são atividades especificamente humanas. O trabalho é a essência do homem que, no decorrer da história, ao aprender a produzir sua própria existência, desenvolveu também a sua formação, logo, essa ação é um processo educativo.

O contexto em que vivenciamos, de globalização da economia e implantação do neoliberalismo, tem conduzido a sociedade a uma inevitável dependência política, econômica e mercadológica, que gera cada vez mais competitividade, assim como a exigência de uma formação atrelada ao desenvolvimento de novas habilidades e competências para a atuação no mercado de trabalho. Mas também, estamos em um tempo, segundo Frigotto (2001), de ampliação do desemprego, de precarização do trabalho e de uma situação de permanente angústia e insegurança daqueles que, para sobreviver, têm apenas sua força de trabalho para vender.

Nessa perspectiva, ao venderem sua força de trabalho como mercadoria em troca de salário, e ao serem pagos por capital-dinheiro, trabalhadores e trabalhadoras, em sua totalidade, integram-se cada vez mais às cadeias produtivas globais, o que leva à urgente necessidade de ampliar, segundo Antunes (2009), a própria definição de 'classe trabalhadora'.

E, a partir desse pressuposto, podemos afirmar que os sujeitos analisados por meio deste estudo pertencem à classe trabalhadora e que quase todos eles conseguiram se inserir no mercado de trabalho após o processo formativo. Dentre os egressos que já trabalhavam antes de realizarem a graduação há relatos de que o trabalho desenvolvido por eles antes e durante o processo formativo foi fundamental para que tivessem maior valorização profissional no mercado de trabalho após a formação superior.

Os trabalhadores egressos, além de estarem inseridos no mercado de trabalho, atuam, em sua maioria, com vínculos de trabalho formal e no setor público de serviço. Diante disso, identificamos que o curso realizado por esses sujeitos influenciou positivamente para a inserção e manutenção destes no mercado, apesar do acirramento pela concorrência e as exigências cada vez maiores por qualificação e capacitação, impostas pelo capital. Entretanto, a maior parte dos trabalhadores egressos não atua na sua área de formação, e sim em diversas outras áreas que, segundo eles próprios, foram escolhidas inicialmente por apresentarem melhores condições financeiras e, depois, por promover valorização profissional.

No que diz respeito ao direito à educação, identificamos que este ele ainda é concebido como um desafio para que seja garantido e efetivado por meio de medidas de universalização do acesso e da per- 
manência, principalmente ao Ensino Superior. Os trabalhadores que conseguiram ingressar na UAB/Polo Cametá fazem parte da exceção de sujeitos da classe trabalhadora que tiveram os seus direitos de acesso e de permanência à educação garantidos, alcançando a formação superior.

Não podemos esquecer que os desafios das universidades públicas são, de acordo com Severino (2008), os mesmos de toda a educação pública, em todos os seus níveis e modalidades, resumindo-se no conflito dilemático que atravessa a realidade social brasileira da atualidade: o confronto entre uma educação que se coloca a serviço do capital e outra que se quer a serviço da construção de uma condição de existência mais humanizada, onde o trabalho é uma mediação essencial do existir histórico das pessoas e não um mero mecanismo da produção para o mercado.

Diante disso, com base nos dados obtidos e nos relatos dos trabalhadores egressos que concluíram o processo formativo na UAB, constatamos que essa instituição pública de ensino superior não se isenta desse desafio conflitante entre duas concepções de educação ofertando, assim, uma formação tanto no aspecto profissional, que se coloca a serviço do mercado, quanto no aspecto humano, que se coloca a serviço da construção de uma condição de existência mais humanizada.

A UAB/Polo Cametá, criada pela Lei Municipal № 245/2013, constitui-se como uma instituição detentora de uma importante função no processo formativo dos trabalhadores, proporcionando-lhes a formação de nível superior, a possibilidade de mudarem sua trajetória de vida e a oportunidade de entrarem no mercado de trabalho. O Polo possibilitou a trabalhadores e trabalhadoras, oriundos de condições econômicas desfavorecidas, de diversos municípios da região, não apenas jovens, mas também adultos e até sujeitos de idade avançada, com condições econômicas desfavorecidas e que ainda não haviam conseguido cursar uma universidade pública na modalidade presencial por diversos motivos - realizarem o Ensino Superior por meio da EaD, conseguindo conciliar sua rotina diária, seu trabalho e seu estudo.

Na UAB, por exemplo, o processo seletivo é especial, de modo a atender às especificidades dos trabaIhadores que já atuam como professores da Educação Básica e não receberam a formação, e também aqueles que ainda vão realizar a formação inicial. De acordo com o Censo da Educação Superior, entre os anos de 2007 e 2017, o número de ingressos no Ensino Superior brasileiro ampliou-se, principalmente em relação à educação a distância, que avançou cerca de três vezes mais $(226,0 \%)$ que os cursos de graduação presencial (19,0\%). No ano de 2017, o volume de ingressos teve um aumento significativo na modalidade EaD (BRASIL, 2017, p. 19).

O Decreto $n^{\circ}$ 5.622, de 19 de dezembro de 2005, no seu Art. 1², caracteriza a EaD como sendo uma modalidade educacional na qual a mediação didático-pedagógica nos processos de ensino e de aprendizagem ocorre com a utilização de meios e tecnologias de informação e comunicação, com estudantes e professores desenvolvendo atividades educativas em lugares ou tempos diversos (BRASIL, 2005). Diante disso, compreendemos que, nessa modalidade de educação, docentes e educandos são mediados por meio das tecnologias, não existindo praticamente interação direta entre estes, exigindo, assim, ainda mais autonomia por parte do aluno em busca da autoaprendizagem.

De acordo com os relatos dos trabalhadores egressos, o curso da UAB os levou a adquirir autonomia de estudar, de se organizar, de fazer cronogramas, de ter seu horário e o seu espaço de estudo. Outro elemento que deve ser considerado é que os trabalhadores egressos faziam grupos de estudo e se encontravam de segunda a quinta-feira para estudar. Isso é o reconhecimento de que a EaD está em propostas que não fomentam o isolamento do aluno, mas sim ensinam a valorizar a solidariedade e a participação nas atividades educacionais.

A UAB/Polo Cametá oferta cursos a distância, e esse tipo de modalidade geralmente não possibilita a vivência universitária, na oportunidade de desenvolver atividades de ensino, pesquisa e extensão, pois, 
o foco está apenas no ensino. De acordo com Arruda e Arruda (2015), o aluno da EaD, em função de ser oriundo de um programa governamental, como o Sistema $U A B$, não é integrado às políticas de pesquisa e extensão e, por conseguinte, não vivencia experiências universitárias completas. Essa desconstrução do tripé ensino, pesquisa e extensão desobedece ao que foi estabelecido na Constituição Federal de 1988, quanto ao princípio de indissociabilidade entre ambos e, por isso, nos leva a pensar que o processo formativo, nesse contexto, resultará em uma formação incompleta e, consequentemente, em um perfil profissional tecnicista e imediatista. Mas, a partir das análises realizadas neste estudo, podemos dizer que os trabalhadores egressos da UAB/Polo Cametá realizaram um curso que atuou tanto na formação técnica quanto humanizada, levando estes a atuarem profissionalmente nessa mesma perspectiva.

Apesar das dificuldades enfrentadas, os egressos destacaram vantagens significativas no processo formativo, como a independência, a autonomia e a integração, estabelecidas entre todos que faziam parte do espaço institucional, uma vez que, além de levá-los a estudarem por conta própria, a formação contribuiu no sentido de induzir os trabalhadores egressos a ressignificarem o papel da EaD no Ensino Superior, atribuindo um novo olhar a essa modalidade.

Como nos mostra Rios e Pimentel (2007), não é a modalidade do ensino que determina a efetividade do aprendizado. A educação, seja ela presencial ou a distância, deve propiciar ao estudante, entre outras coisas, alguns aspectos fundamentais para sua formação como cidadão: consciência crítica, criativa e participativa; formação sólida que permita apreender conteúdos que fundamentem a análise e a interpretação da realidade; e vinculação da teoria e prática, contextualizada nos aspectos social, econômico, político e cultural.

\section{A UAB e a Formação do Trabalhador}

A Universidade Aberta do Brasil foi instituída oficialmente pelo Decreto $n^{\circ} 5.800$, de 8 de junho de 2006, tendo em vista o disposto nos Arts. 80 e 81 da Lei de Diretrizes e Bases da Educação Nacional - LDB (Lei n 9.394/1996), para desenvolver a modalidade de EaD, com a finalidade de expandir e interiorizar a oferta de cursos e programas de Educação Superior no Brasil.

O Sistema UAB, criado pelo Ministério da Educação, tem a particularidade de realizar parceria com as instituições públicas de Ensino Superior, dos três níveis governamentais: federal, estadual e municipal. Além disso, segundo o Decreto Nacional no 5.800/2006, a UAB tem como objetivos: oferecer, prioritariamente, cursos de licenciatura e de formação inicial e continuada de professores da Educação Básica; oferecer cursos superiores nas diferentes áreas do conhecimento; ampliar o acesso à educação superior pública; reduzir as desigualdades de oferta de Ensino Superior entre as diferentes regiões do país; estabelecer amplo sistema nacional de educação superior a distância (BRASIL, 2006).

As políticas públicas para ensino superior a distância no Brasil, por meio da ampliação da oferta de vagas, estão atreladas a uma tentativa de qualificar professores da educação básica. Assim, a maioria dos cursos a distância são licenciaturas. Isso pode estar relacionado à busca pela inclusão de indivíduos que estão fora do sistema educacional e pela tentativa de melhorar os índices da educação no país, com base no pressuposto de que o nível de qualificação dos professores é diretamente proporcional à qualidade do ensino e ao nível de desempenho dos alunos (MENDONÇA et al., 2020, p. 159).

Essas políticas se materializam no contexto local por meio do Polo Cametá, no estado do Pará, regulamentado pela Lei Municipal n 245, de 20 de setembro de 2013, e atua no município há dez anos, tendo 
sua aula inaugural ocorrida em 22 de agosto de 2009, oferecendo inicialmente apenas o curso de Graduação de Licenciatura Plena em Matemática.

O Polo é mantido a partir da parceria do Ministério da Educação, via UAB, com a Prefeitura Municipal de Cametá. O Polo oferta cursos em períodos não regulares, nos quais a metodologia de ensino se desenvolve por meio de tutorias com aulas a distância e presenciais, uma ou duas vezes na semana. Os tutores ingressam por meio de concurso feito pelas instituições parceiras da UAB, como a Universidade Federal do Pará (UFPA), a Universidade do Estado do Pará (UEPA), a Universidade Federal de Ouro Preto (UFOP), de Minas Gerais, e a Universidade Federal Fluminense (UFF), do Rio de Janeiro.

Tabela 1: Número de egressos da UAB/Polo Cametá que concluíram o processo formativo no período de 2014 a 2018 e número de egressos que foram contatados no ano de 2019.

\begin{tabular}{|l|c|c|c|}
\hline \multicolumn{1}{|c|}{ Cursos pesquisados } & Ano de conclusão & $\mathbf{N}^{\circ}$ total de egressos & $\begin{array}{c}\mathbf{N}^{\circ} \text { de egressos } \\
\text { contatados }\end{array}$ \\
\hline Licenciatura em Matemática & 2014 & 26 & 11 \\
\hline Licenciatura em Matemática & 2016 & 18 & 09 \\
\hline Bacharelado em Administração & 2016 & 31 & 08 \\
\hline Licenciatura em Matemática & 2018 & 27 & 08 \\
\hline Total & & $\mathbf{1 0 2}$ & $\mathbf{3 6}(\mathbf{3 5 \% )}$ \\
\hline
\end{tabular}

Fonte: Elaboração própria.

Durante o período da pesquisa, compreendemos que o Polo Cametá tem uma infraestrutura física, tecnológica e de pessoal adequada aos projetos pedagógicos dos cursos ou de desenvolvimento da instituição de ensino; tem biblioteca física com espaço para estudos dos discentes, laboratórios de matemática, biologia e informática, este último equipado com computadores com acesso à internet; além de ter também o Ambiente Virtual de Aprendizagem (AVA), a plataforma Moodle, que, segundo Kendler e Oliveira (2015), é uma plataforma virtual e um dos softwares mais utilizados mundialmente por instituições de ensino, que tem diversas funcionalidades, como: ferramentas de interação (chat, enquete, fórum de discussão); atividades e tarefas com os alunos (diários, lição, exercícios); ferramentas de avaliação (avaliação do curso, notas, questionário); fontes de conteúdo e informação (artigos, livros eletrônicos, biblioteca, perguntas frequentes); e utilizada também para a interação entre o aluno e o tutor.

As ações desenvolvidas no âmbito dos cursos a distância possibilitam repensar a organização do espaço da ação educativa e devem ter por objetivo assegurar a promoção do ser humano, minimizando os efeitos marginalizadores, excludentes, seletivos e impessoais do sistema educacional tradicional. Assim, em qualquer processo de ensino-aprendizagem, quer seja presencial ou a distância, o papel do professor é causar o desequilíbrio no aluno, agindo como mediador entre ele e o conhecimento. A Educação a Distância deve propiciar essa interação de maneira adequada para que o discente seja desafiado a construir o seu conhecimento (CUSTÓDIO et al., 2019, p. 05).

Com base no pensamento dos autores citados e nas entrevistas realizadas com os trabalhadores egressos, destacamos que a UAB/Polo Cametá tem importante função social no atendimento das demandas da sociedade. Isso fica evidente na fala do Egresso D, quando perguntado se a instituição contribui positivamente para o município de Cametá. 
A UAB contribui muito, na verdade assim, muitas pessoas não fazem um curso presencial, um curso intensivo ou extensivo, por conta da questão de trabalhar, e muitas vezes, essas pessoas acabam indo para uma instituição particular. Então, a UAB é um link entre as instituições públicas que ofertam cursos superiores, ofertando o curso a distância [...] Por isso, eu digo que socialmente ela contribui muito para o município de Cametá e não só para esse município, mas para toda região, porque na minha turma tinha alunos de Mocajuba, Areião, Carapajó, Igarapé-Miri, Baião e Oeiras do Pará, então, a turma era composta por alunos de diversos municípios (Egresso D, 2019).

A UAB também tem uma importante função social, enquanto instituição de Ensino Superior na formação de trabalhadores que precisam conciliar trabalho e estudo; então, podemos dizer que esta cumpre eficazmente um dos seus objetivos, que é o de ampliar o acesso à educação superior pública, como é possível observar na fala do Egresso B.

Ela dá oportunidade para os jovens, até para pessoas de idade mais avançada terem a formação superior. Eu tive que trabalhar, trabalhava durante a semana, mas final de semana ia pra aula presencial [...]. Então, a UAB é muito importante sim para o município. Pra mim, o curso foi bastante produtivo, eu saí de lá um profissional que procuro sempre fazer o melhor baseado nesse curso, nas aprendizagens e vivências que adquiri (Egresso B, 2019).

Os cursos de Licenciatura em Matemática e de Bacharelado em Administração Pública, oferecidos pela UAB/Polo Cametá que foram analisados nesta pesquisa, realizaram-se em parceria com a UFPA, apresentando um quantitativo de 102 trabalhadores que concluíram o processo formativo no período de 2014 a 2018.

\section{Perfil e Inserção/Manutenção no Mercado de Trabalho}

Os dados obtidos com a aplicação do questionário nos possibilitaram inferir em relação ao perfil socioeconômico, que os trabalhadores egressos estão na faixa etária entre 24 e 54 anos, sendo que 20 desses sujeitos são do gênero masculino $(55,6 \%)$ e 16 do gênero feminino $(44,4 \%)$, apresentando estado civil: solteiros (47,2\%) e casados (27,8\%). Em sua maioria são originários da zona urbana $(69,4 \%)$, principalmente do município de Cametá (72,2\%).

Após a formação superior, uma proporção ainda mais elevada reside na zona urbana (80,6\%), localizando-se em diversos municípios do estado do Pará, como Belém, Mocajuba, Tomé-Açu, Oeiras do Pará, Limoeiro do Ajuru, Abaetetuba, Capanema e Igarapé-Miri, entretanto, a maioria ainda é residente do município de Cametá (50,0\%), onde se localiza a instituição formadora. Quanto à escolaridade dos pais (50,0\%) e das mães (36,1\%) dos egressos, estes, em sua maioria, têm apenas o Ensino Fundamental incompleto, ou seja, um baixo nível de escolaridade, sendo que somente $5,6 \%$ dos pais e $13,9 \%$ das mães dos trabaIhadores egressos alcançaram uma formação de nível superior.

Numa compreensão histórica e ontológica, o trabalho é a ação do ser humano ao agir, transformar e adaptar a Natureza de acordo com as suas necessidades, ou seja, o trabalho não é dado aos indivíduos naturalmente, mas estes precisam produzi-lo (SAVIANI, 2007). Diante disso, inferimos que uma significativa parte dos egressos $(86,1 \%)$ já exercia algum tipo de trabalho durante a graduação e após o processo formativo uma proporção ainda mais elevada desses sujeitos, está inserida no mercado de trabalho $(91,7 \%)$; sendo apenas 8,3\% que afirmaram não exercer profissão/ocupação alguma, mesmo ao ser expli- 
citado que o trabalho é toda atividade produtiva, tendo ou não vínculo empregatício. E a maior parte desses trabalhadores egressos atualmente $(77,8 \%)$ está realizando trabalho com vínculo formal, e somente 13,9\% com vínculo de trabalho informal. Esses dados podem ser visualizados na Figura 1, a seguir:
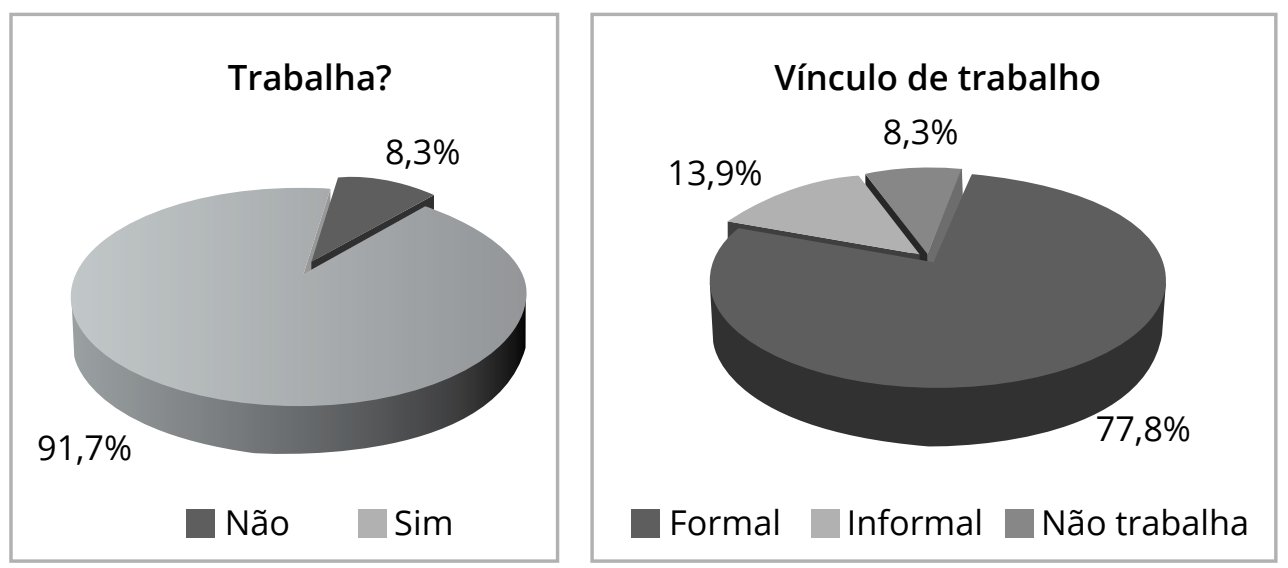

Figura 1: Percentuais em relação ao trabalho e vínculo de serviço dos egressos da UAB/Polo Cametá no ano de 2019.

Fonte: Dados da pesquisa.

A inserção profissional, antes e durante a graduação, foi essencial para os egressos terem, após o processo formativo, valorização profissional. E atualmente o equivalente a 50,0\% dos trabalhadores egressos têm um tempo de trabalho de mais de três anos nas atividades laborais que desenvolvem, sendo que $44,4 \%$ ganham uma renda mensal individual em torno de 1 a 2 salários mínimos, e 63,9\% dos trabalhadores egressos atuam no setor público, $16,7 \%$ atuam no setor privado e apenas $11,1 \%$ atuam como autônomos, ou seja, que trabalham por conta própria, não têm um emprego fixo com vínculo empregatício.

Diante da relevância da EaD como ferramenta mediadora de conhecimento, considera-se que dois argumentos são recorrentes na defesa dos cursos de graduação a distância e têm servido de justificativa para a expansão desse setor no Brasil, que são: a possibilidade de democratizar o acesso ao ensino superior e a necessidade de adotar novas tecnologias nos processos de formação. Nessa perspectiva, Moreira e Dal Molin (2019) corroboram que a EaD, nos últimos anos, cresceu vigorosamente no Brasil, alcançando um expressivo número dos que passaram a ter acesso ao Ensino Superior. Dessa forma, a expansão da EaD está cumprindo sua missão de favorecer, por meio das plataformas digitais, àqueles que, por diversos motivos - socioeconômico, de tempo ou distância geográfica - não teriam acesso ao conhecimento e à formação acadêmica. (OLIVEIRA; SANTOS, 2020, p. 120)

Os trabalhadores egressos, ao serem indagados se suas atividades laborais 'sofriam' a interferência da precariedade do trabalho que vivenciavam, fizeram relatos que nos levaram a uma reflexão sobre a relação público/privado, visto que o Egresso A, que trabalha há mais de três anos no setor público, como professor de Matemática, relatou o contexto social de pobreza onde desenvolve seu trabalho; enquanto que o Egresso B, que atua no setor privado, também há mais de três anos, como professor de Matemática, afirma que sua atividade laboral, não 'sofre' a interferência da precariedade do trabalho que ele vivencia.

A dificuldade é muito grande. A precariedade é muito grande em todos os sentidos, e principalmente porque eu trabalho em uma região que é a mais pobre do Estado, a região do Marajó, que está entre os 10 menores IDH do Brasil (Egresso A, 2019). 
De acordo com Antunes (2009), os sujeitos brasileiros que terminam seus estudos não mais têm garantido o seu espaço no mercado de trabalho, devido à subordinação do capital vigente. Diante disso, vimos que a maioria dos trabalhadores egressos $(61,1 \%)$ não atua na sua área de formação, mas sim desempenham outras atividades laborais, como: vendedor, gerente, bancário, carteiro, atendente, secretário escolar, técnico em enfermagem, vigilante, autônomo e etc. Entretanto, mesmo que a maioria desses sujeitos não atue na sua área de formação, 61,1\% também alegam estarem satisfeitos com sua profissão/ ocupação atual. Na Figura 2, é possível visualizar as situações aqui descritas.

\section{Trabalha na sua área de formação?} $30,6 \%$

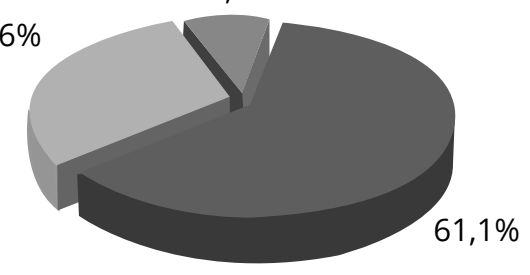

Não
Sim Não trabalho

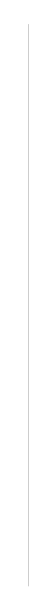

\section{Está satisfeito com seu trabalho atual?}

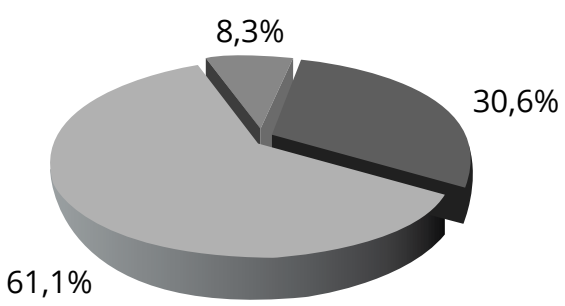

Não Sim Não trabalho

Figura 2: Percentuais em relação à atuação na área de formação e satisfação do trabalho atual dos egressos da UAB/Polo Cametá no ano de 2019.

Fonte: Dados da pesquisa.

Como a maioria dos trabalhadores egressos não atua na sua área de formação, indagamos a eles sobre os principais motivos que os levaram à escolha do trabalho atual. Eles relataram que a escolha foi por melhores condições financeiras e por valorização profissional, conforme se observa na fala do Egresso D.

Eu não atuo como professor de matemática, eu sou técnico administrativo na UFPA, Campus de Cametá. E a escolha de estar trabalhando atualmente nessa área administrativa, primeiro foi a questão financeira, mas ao longo das minhas vivências, eu percebi que isso é muito importante, e não apenas financeiramente (Egresso D, 2019).

Os trabalhadores egressos, ao serem indagados se estavam satisfeitos ou realizados profissionalmente, relataram, em sua maioria, que estavam satisfeitos, tanto os que atuavam na sua área de formação quanto aqueles que não atuavam. Apresentamos, a seguir, a fala do Egresso $A$, que atua na sua área como professor de Matemática.

Minha profissão é professor, e quando eu escolhi essa profissão, eu já sabia que professor ganhava mal, que trabalhava muito, que tinha dificuldade de acesso. Mas, isso a gente concebe da seguinte maneira, o salário é o de menos quando você encontra um aluno seu que diz: professor estou muito bem, eu conseguir passar no ENEM. Então, o que mais me realiza é esse lado, o lado emotivo, o lado de que eu cumprir com meu dever (Egresso A, 2019).

A UAB/Polo Cametá, segundo o Decreto Municipal n 97/2013, tem como objetivo geral, oportunizar à comunidade da região meios para que as pessoas possam se profissionalizar por meio de cursos a distân- 
cia, de qualidade e gratuitos, atendendo, assim, à demanda às necessidades do mercado local e regional, com uma metodologia de tempo e espaço condizentes às condições do alunado (CAMETÁ, 2013).

Os dados mostram que a escolha dos egressos pela UAB/Polo Cametá se deu por dois fatores: pela gratuidade do curso, correspondendo a 41,7\%, depois pela qualidade/reputação da Instituição de Ensino Superior - IES 33,3\%. E, em relação à escolha dos cursos, os trabalhadores egressos, em sua maioria $(36,1 \%)$, optaram por estes como sendo o curso desejado para a formação superior, e $27,8 \%$ devido à flexibilidade da EaD, pois, os alunos veem nesses cursos uma oportunidade de conciliar sua rotina diária a seu trabalho e estudo.
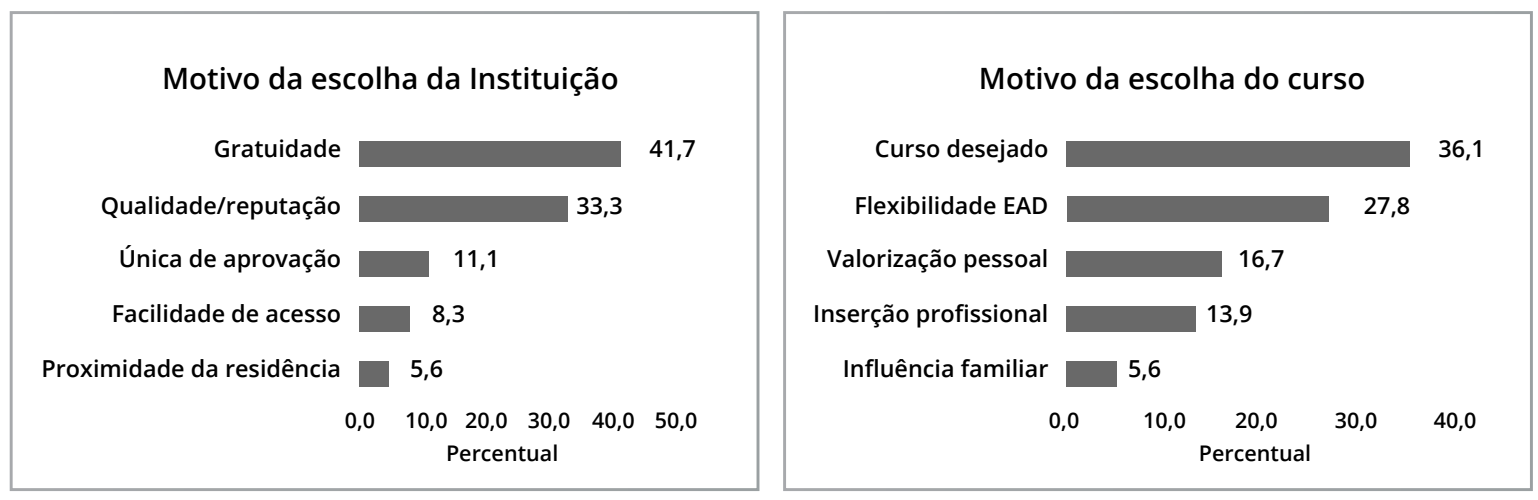

Figura 3: Percentuais em relação à escolha da instituição e escolha do curso dos egressos da UAB/Polo Cametá no ano de 2019.

Fonte: Dados da pesquisa.

Ainda há dificuldade de acesso à universidade pública por parte dos trabalhadores, principalmente nas que ofertam cursos na modalidade presencial. A UAB é uma instituição pública que, por meio da EaD, dá oportunidade para os trabalhadores alcançarem a formação superior, pois, os sujeitos desta pesquisa afirmam que se sentem satisfeitos com a formação recebida, relatando que esta correspondeu às suas expectativas, conforme diz o Egresso B:

\begin{abstract}
Correspondeu sim, e me sinto muito satisfeito. As pessoas, às vezes, menosprezam um curso a distância, mas na verdade eu falo que o curso a distância é melhor que o presencial, porque você tem que estudar, criar uma autonomia, ou você aprende ou você não vai ser um bom profissional. E hoje eu me considero um bom profissional por causa desse curso (Egresso B, 2019).
\end{abstract}

No que diz respeito à formação profissional e humana, constatamos que, no processo formativo dos egressos, houve uma relação profunda entre ambas, demonstrando que o curso atuou tanto na formação técnica quanto humanizada, sendo que uma das maiores dificuldades no processo formativo foi em relação à comunicação, ocasionada devido à ineficiência, muitas vezes, do acesso à internet, principalmente nos primeiros anos da implantação da UAB/Polo Cametá. Contudo, foram enaltecidas pelos trabalhadores egressos, como vantagens do processo formativo, a independência e a autonomia adquirida por eles, assim como a integração estabelecida entre aluno e tutor, aluno e aluno, aluno e demais profissionais da instituição. 


\section{Conclusão}

Os resultados desta pesquisa nos possibilitam afirmar que a UAB/Polo Cametá contribuiu positivamente no processo formativo dos trabalhadores egressos, proporcionando uma formação tanto no aspecto profissional quanto humano por meio da EaD, sendo que esta apresentou como diferencial a possibilidade de Formação Superior ao trabalhador e a atuação com qualidade.

O processo metodológico desenvolvido durante essa pesquisa possibilitou uma reflexão sobre a relação trabalho e educação no contexto universitário por meio da EaD, voltados para a formação de professores, embasada em uma análise do perfil e das características referentes à inserção/manutenção no mercado de trabalho desses egressos.

Explicita-se que a UAB contribui para o processo de democratização do ensino superior, voltado para a formação de trabalhadores, especificamente por meio da formação de professores, na busca de uma perspectiva de formação humanizada que proporcionou aos seus egressos satisfação em seu trabalho.

Conclui-se ainda que muitas dificuldades foram enfrentadas no processo formativo, principalmente referente aos recursos tecnológicos no início do curso, mas também muitas conquistas foram alcançadas, como a independência e a autonomia em relação ao estudo, destacadas pelos sujeitos da pesquisa. Praticamente, a totalidade dos egressos está inserida no mercado de trabalho. $E$, no que tange à área de formação, a maioria desses sujeitos não atua nela; entretanto, contraditoriamente, sentem-se satisfeitos com a formação recebida, afirmando que ela correspondeu às suas expectativas, assim como sentem-se satisfeitos com a atividade laboral que desenvolvem atualmente, apesar de muitas sofrerem a interferência da precariedade do trabalho que se vivencia sob a lógica do capital. Além disso, explicitaram-se, por meio dessa pesquisa, significativas contribuições de uma universidade pública e gratuita, que oferta cursos por meio da EaD para a formação do trabalhador brasileiro.

\section{Referências}

ANDRIOLA, W. B. (2014). Estudo de egressos de cursos de graduação: subsídios para a autoavaliação e o planejamento institucionais. Educar em Revista, Curitiba, Brasil, n. 54, p. 203-219, out./dez. Editora UFPR, 2014. Disponível em: http://www.scielo.br/pdf/er/n54/a13n54.pdf. Acesso em: 12 jul. 2019.

ANTUNES, R. (2009). Os sentidos do trabalho: ensaio sobre a afirmação e a negação do trabalho. São Paulo, SP: Boitempo.

ARRUDA, E. P., \& ARRUDA, D. P. (2015). Educação a Distância no Brasil: Políticas Públicas e Democratização do acesso ao Ensino Superior. Educação em Revista, 31(3), 321-338. Disponível em: http://www. scielo.br/pdf/edur/v31n3/19826621-edur-31-03-00321.pdf. Acesso em: 12 jul. 2019.

BRASIL. Censo da Educação Superior. Brasília, DF: MEC/INEP, 2017.

BRASIL. Decreto n 5.800. (2006, 08 de junho). Dispõe sobre o Sistema Universidade Aberta do Brasil - UAB. Disponível em: http://www.planalto.gov.br/ccivil 03/ Ato2004-2006/2006/Decreto/D5800.htm. Acesso em: 12 jul. 2019.

BRASIL. Decreto $n^{\circ}$ 5.622. (2005, 19 de dezembro). Regulamenta o Art. 80 da Lei n $^{\circ}$ 9.394, de 20 de dezembro de 1996, que estabelece as diretrizes e bases da educação nacional. Disponível em: http:// www.planalto.gov.br/ccivil 03/ Ato2004-2006/2005/Decreto/D5622.htm. Acesso em: 12 jul. 2019.

BRASIL. Lei n 9.394. (1996, 20 de dezembro). Estabelece as diretrizes e bases da educação nacional. Brasília, DF: Presidência da República, [2017]. Disponível em: http://www.planalto.gov.br/ccivil_03/ leis/19394.htm. Acesso em: 12 jul. 2019. 
CAMETÁ. Decreto Municipal no 97. (2013, 29 de julho). Lei Municipal de Criação do Polo de Apoio Presencial da Universidade Aberta do Brasil UAB/Cametá, n 245 de 20 de setembro de 2013. Cametá, PA: PMC, 2013.

CUSTÓDIO, S. G. et al. (2019). O Papel do Tutor na Humanização da Aprendizagem na Educação a Distância. EaD em Foco, V9, e767. Disponível em: https://doi.org/10.18264/eadf.v9i1.767. Acesso em: 07 out. 2020.

CUNHA, L. A. (1989). Qual universidade? São Paulo, SP: Cortez.

FRANCO, M. L. (2008). Análise de conteúdo. (3a. ed.). Brasília, DF: Liber Livro Editora.

FRIGOTTO, G. (1991). 0 enfoque da dialética materialista histórica na pesquisa educacional. In Fazenda, I. (org.). Metodologia da pesquisa educacional (pp. 20). São Paulo, SP: Cortez.

FRIGOTTO, G. (2001). Educação e Trabalho: bases para debater a Educação Profissional Emancipadora. Perspectiva, 19(1), 71-87. Disponível em: https://www.feis.unesp.br/Home/DSAA/DS AA/ProjetoGQTSCM/documentos/educaca o/04 frigotto.pdf. Acesso em: 12 jul. 2019.

GERHARDT, T. E.; SILVEIRA, D. T. (2009). Métodos de pesquisa. Porto Alegre, RS: Editora da UFRGS.

IBGE. Instituto Brasileiro de Geografia e Estatística. (2010). Censo demográfico. Rio de Janeiro, RJ: IBGE.

KENDLER, V., \& OLIVEIRA, L. C. V. de. (2015). Experiência de professores de uma instituição pública no uso das novas tecnologias da informação e da comunicação na educação a distância. Belo Horizonte: Universidade FUMEC.

LUDKE, M., \& ANDRÉ, M. (1986). Pesquisa em educação: abordagens qualitativas. São Paulo, SP: EPU.

MARCONI, M. de A., \& LAKATOS, E. M. (2003). Fundamentos de metodologia científica. (5a. ed.). São Paulo, SP: Atlas.

MENDONÇA, J. R. C. et al. (2020). Políticas públicas para o Ensino Superior a Distância: um exame do papel da Universidade Aberta do Brasil. Ensaio: aval. pol. públ. Educ., Rio de Janeiro, v.28, n.106, p. 156-177, jan./mar. Disponível em: https://doi.org/10.1590/s0104-40362019002801899. Acesso em: 07 out. 2020.

OLIVEIRA, F. A.; SANTOS, A. M. S. dos. (2020). Construção do Conhecimento na Educação a Distância: Descortinando as Potencialidades da EaD no Brasil. EaD Em Foco, V10, e799. Disponível em: https:// doi.org/10.18264/eadf.v10i1.799. Acesso em: 07 out. 2020.

RIOS, J. A., \& PIMENTEL, R. G. (2007). Educação a distância e o seu grande desafio: o educando como sujeito de sua própria aprendizagem. Disponível em: http://extensao2.nead.ufsj.edu.br/site/. Acesso em: 12 jul. 2019.

RUDIO, F. V. (2007). Introdução ao projeto de pesquisa científica. (34a. ed.). Petrópolis, RJ: Vozes.

SAVIANI, D. (2007). Trabalho e educação: fundamentos ontológicos e históricos. Rev. Bras. Educ., 12(34), 152-165, 2007. Disponível em: http://www.scielo.br/pdf/rbedu/v12n34/a12v1234.pdf. Acesso em: 12 jul. 2019.

SEVERINO, A. J. (2008). 0 ensino superior brasileiro: novas configurações e velhos desafios. Educar, 31, 73-89, 2008. Disponível em: http://www.scielo.br/pdf/er/n31/n31a06. Acesso em: 12 jul. 2019. 